\title{
Low Temperature Glycerolysis as a High FFA Pre-Treatment Method for Biodiesel Production
}

\author{
Godlisten G. Kombe ${ }^{1 *}$, Abraham K. Temu ${ }^{1}$, Hassan M. Rajabu ${ }^{2}$, \\ Godwill D. Mrema ${ }^{1}$, Keat Teong Lee ${ }^{3}$ \\ ${ }^{1}$ Department of Chemical and Mining Engineering, College of Engineering and Technology, \\ University of Dar es Salaam, Dar es Salaam, Tanzania \\ ${ }^{2}$ Department of Energy Engineering, College of Engineering and Technology, \\ University of Dar es Salaam, Dar es Salaam, Tanzania \\ ${ }^{3}$ School of Chemical Engineering, Universiti Sains Malaysia, Pinang, Malaysia \\ Email: "kombe@live.com, atemu@udsm.ac.tz,hmrajabu@udsm.ac.tz,mremag@udsm.ac.tz, chktlee@eng.usm.my
}

Received July 26, 2013; revised August 26, 2013; accepted September 5, 2013

Copyright (C) 2013 Godlisten G. Kombe et al. This is an open access article distributed under the Creative Commons Attribution License, which permits unrestricted use, distribution, and reproduction in any medium, provided the original work is properly cited.

\begin{abstract}
A novel low temperature glycerolysis process for lowering free fatty acid (FFA) in crude jatropha oil for alkali catalyzed transesterification has been developed. The response surface methodology (RSM) based on central composite design was used to model and optimize the glycerolysis efficiency under three reaction variables namely; reaction time, temperature and glycerol to oil mass ratio. The optimum conditions for highest glycerolysis efficiency of $98.67 \%$ were found to be temperature of $65^{\circ} \mathrm{C}$, reaction time of 73 minutes and $2.24 \mathrm{~g} / \mathrm{g}$ glycerol to oil mass ratio. These conditions lower the high free fatty acid of crude jatropha oil from $4.54 \%$ to $0.0654 \%$ which is below $3 \%$ recommended for alkali catalyzed transesterification. The pre-treated crude jatropha oil was then transesterified by using homogeneous base transesterification resulting to a conversion of $97.87 \%$. The fuel properties of jatropha biodiesel obtained were found to be comparable to those of ASTM D6751 and EN 14214 standards. The process can also utilize the crude glycerol from the transesterification reaction, hence lowering the cost of biodiesel. The glycerolysis is easier implemented than acid esterification thereby avoiding the need for neutralization and alcohol removal step.
\end{abstract}

Keywords: Biodiesel; Glycerolysis; Free Fatty Acid; Re-Esterification

\section{Introduction}

The use of edible grade oils as feedstocks for fuel competes with food supply in the long-term and accounts for the higher price of biodiesel, as the cost of raw materials accounts for $60 \%$ to $80 \%$ of the total cost of biodiesel fuel [1]. An alternative way of reducing the biodiesel production costs is to use less expensive feedstocks which do not compete with food supply and land for food cultivation such as non-edible oils, animal fats, waste food oil and by-products of refining vegetable oils [2]. Transesterification reaction can be uncatalysed, basecatalyzed, acid-catalyzed, or enzyme-catalyzed. The homogeneous base-catalyzed transesterification process is widely used industrially due to the fact that it is kinetically much faster and it has been proven to be economically viable [3]. According to the report by Bacovsky, Körbitz, Mittelbach and Wörgetter [4] on the status of

\footnotetext{
${ }^{*}$ Corresponding author.
}

biodiesel production technology, most of the commercialized biodiesel production technology utilizes a homogeneous base-catalyzed transesterification. However, the main drawback of this technology is its sensitivity to the purity of the reactants being very sensitive to both water and free fatty acids content [5]. Most of non-edible oil feedstocks are high in free fatty acids and cannot easily undergo homogeneous base transesterification to produce biodiesel due to concurrent soap formation of the free fatty acids with the catalyst. The excessive amounts of soap formed significantly interfere with the washing process by forming emulsions, thus leading to substantial yield losses [6]. The reaction can only tolerate FFA content of up to $3 \%$ in the feedstock without affecting the process negatively as suggested by Knothe, Van Gerpen and Krahl [7]. Free fatty acid lower than 3\% is recommended for higher conversion efficiency [8]. Pretreatments of non-edible oils for lowering of the FFA in feedstock for base catalyzed transesterification are there- 
fore inevitable.

The chemical re-esterification (glycerolysis) process has the capability of converting the free fatty acid back to their respective glyceride molecule. This technique involves adding glycerol to the high FFAs feedstock and heating it to temperature of about $200^{\circ} \mathrm{C}$, with a metallic catalyst such as zinc chloride and zinc dust or without catalyst. The glycerol reacts with the FFAs to form monoglycerides, diglycerides and triglycerides [9]. It produces a low FFAs feedstock that can be processed using traditional homogeneous base transesterification technique. The advantage of this approach is that no alcohol is needed during the pre-treatment and the water formed from the reaction can be immediately vaporized and vented from the reaction mixture. Also the process has the potential of utilizing glycerol, a by-product from transesterification thereby lowering the cost of biodiesel. However, the drawbacks of this method are its high temperature requirement, relatively slow reaction rate and being limited by equilibrium, having two liquid phases, where the solubility of glycerin is rather limited in triglycerides [10]. This has limited the application of glycerolysis in pre-treatment of FFAs for biodiesel production.

Despite of its potentiality in lowering high FFA, glycerolysis process has been commonly used to produce monoglycerides (MG) and diglycerides (DG), which are widely used as surfactants and emulsifiers in food, cosmetic, and pharmaceutical products [11]. The glycerolysis process can be carried out via enzymatic, alkaline and acid catalyzed reactions [11]. Most of the existing literature on glycerolysis is on the production of MG and DG and utilizes high temperature and low pressure in the process. The literature also shows that the important variables that affect the glycerolysis reaction with respect to $\mathrm{MG}$ and $\mathrm{DG}$ production, are reaction temperature, type and amount of catalyst, molar ratio of glycerol to oil, the mixing intensity and the reaction time [12].

In this study, the low temperature base catalyzed glycerolysis has been tried for the first time with the application of surface response methodology to optimize pre-treatment of high FFA in jatropha oil for the production of biodiesel via homogeneous base catalyst. For the first time, the glycerolysis has been done at low temperature and without application of pressure and compared with the existing literature.

\section{Material and Methods}

\subsection{Materials}

Jatropha curcas seeds were purchased from the free market in Arusha, Tanzania. The crude oil was extracted mechanically at the University of Dar es salaam, using Chinese oil expeller, Model YZS-120 with a capacity for $200-300 \mathrm{~kg} / \mathrm{h}$. The dark greenish yellow color oil ex- tracted was allowed to settle for $24 \mathrm{~h}$ before it was carefully decanted. The oil was then analyzed using AOCS Methods and was found to have $4.54 \%$ of free fatty acid, $181.6 \mathrm{mg} / \mathrm{g}$ of saponification, $0.12 \%$ moisture content and an oxidative stability of $14.5 \mathrm{~h}$. All chemicals used in the experiments such as methanol (99.5\%), sulphuric acid (99\% pure) and glycerol (>99\%), $\mathrm{NaOH}(99 \%)$ in pellet form were of analytical grade.

\subsection{Experimental Procedure}

\subsubsection{Chemical Re-Esterification (Glycerolysis)}

Response surface methodology (RSM) was employed to investigate the variation of glycerolysis efficiency with respect to operating parameters including temperature, time, and glycerol to oil mass ratio. The composition of the three variables was designed by central composite design (CCD) approach. A 24 full-factorial central composite design (CCD) for three independent variables at five levels was employed and the total number of experiments was $20=\left(2^{\mathrm{k}}+2 \mathrm{k}+6\right)$, where $\mathrm{k}$ is the number of independent variables [13]. Glycerolysis reaction was carried out in a glass batch reactor equipped with IKA RW20 mechanical digital stirrer and Barnstead BI electro thermal heating instrument.

Crude jatropha oil was heated and maintained at a given set temperature. $\mathrm{NaOH}$ catalyst $1.75 \%$ wt of oil was dissolved in glycerol before mixing with oil at 800 rpm using IKA RW20 mechanical digital stirrer. The experimental factors selected for optimization and their respective values are provided in Table $\mathbf{1}$. The variables were generated using Design-Expert ${ }^{\mathbb{B}} 7$ software based on the preliminary trial experiments.

Experiments were carried out in a random manner to minimize the effects of the uncontrolled factors. The reaction product mixture was then poured into a separating funnel and allowed to settle for 3 hours. The top layer comprised of oil, whereas the bottom layer contained glycerol, dissolved catalyst and other minor components from the oil. The final amount of FFA was established and the glycerolysis efficiency was determined using Equation (1).

$$
\eta=\left(1-\frac{F F A_{\text {final }}}{F F A_{\text {initial }}}\right) \times 100 \%
$$

Table 1. Experimental ranges and levels of the independent variables.

\begin{tabular}{ccccccccc}
\hline \multirow{2}{*}{ Variables } & \multirow{2}{*}{ Coding } & Unit & \multicolumn{7}{c}{ Level } \\
\cline { 5 - 9 } & & & $-\mathbf{1 . 6 8}$ & $\mathbf{- 1}$ & $\mathbf{0}$ & $\mathbf{1}$ & $\mathbf{1 . 6 8}$ \\
\hline Temperature & $A$ & ${ }^{\circ} \mathrm{C}$ & 30 & 42 & 60 & 78 & 90 \\
Glycerol to oil mass ratio & $B$ & $\mathrm{~g} / \mathrm{g}$ & 0.66 & 1 & 1.5 & 2 & 2.34 \\
Time & $\mathrm{C}$ & $\mathrm{min}$ & 35 & 45 & 60 & 75 & 85 \\
\hline
\end{tabular}


where:

- $\quad \eta=$ Glycerolysis efficiency

- $F F A_{\text {initial }}=$ Free fatty acid of crude oil

- $F F A_{\text {final }}=$ Free fatty acid of crude oil after pre-treatment

The Design-Expert ${ }^{\circledR} 7$ (Stat-Ease Inc., Minneapolis, USA) statistical software was used for regression and graphical analysis of the data obtained. The glycerolysis efficiency was calculated using Equation (1). The glycerolysis efficiency as response variable was fitted in a second-order model in order to correlate the response variable to the independent variable. The quality of fit for the model was evaluated by the coefficients of determination $\left(R^{2}\right)$ and its regression coefficient significance ANOVA was checked with Fisher's test (F-test) [14]. Response surfaces were developed using a quadratic polynomial equation obtained from regression analysis of experimental data.

\subsubsection{Production of Biodiesel}

Pre-treated oil with low FFA was heated to $60^{\circ} \mathrm{C}$ in the transesterification glass batch reactor, as shown in Figure 1 and stirred at $800 \mathrm{rpm}$ with IKA RW20 mechanical digital stirrer. The sodium hydroxide $(\mathrm{NaOH})$ catalyst $1.77 \%$ based on oil weight was dissolved in the required amount of methanol (methanol:oil $=9.3: 1$ ) using ultrasonic bath elmasonic SH075EL at $50^{\circ} \mathrm{C}$ and added to oil. The reaction was conducted for 2 hours after which the resulting product was put into a separating funnel and allowed to settle for 3 hours, where two phases were distinct; biodiesel on top and the glycerol at the bottom. The two phases were separated and the excess methanol in biodiesel was recovered by using a rotarvap.

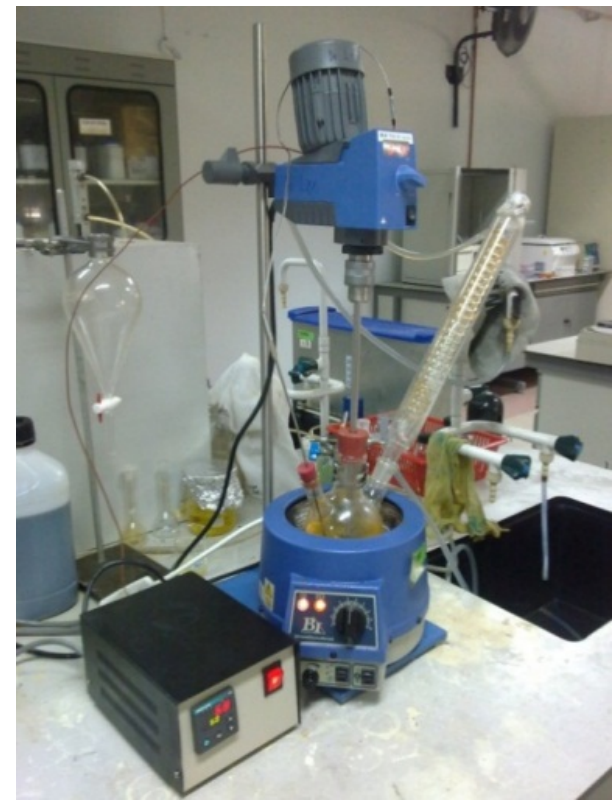

Figure 1. Transesterification experimental setup.

\subsubsection{Fuel Properties}

The biodiesel fuel properties namely, gross calorific value, density at $15^{\circ} \mathrm{C}$, kinematic viscosity at $40^{\circ} \mathrm{C}$, iodine value, oxidation stability, pour point, acid value, and FAME content were determined as per ASTM D6751 and EN 14214 standards [15,16].

\section{Results and Discussions}

\subsection{Glycerolysis}

The response surface design yielded a total of 20 runs in a random order with their corresponding glycerolysis efficiencies as presented in Table 2.

A quadratic model was suggested due to its highest order polynomial with significance additional terms and non-aliased model. The model equation based on the actual values for the glycerolysis efficiency is expressed by Equation (2).

$$
\begin{aligned}
\eta= & 66.72-0.83 A+0.57 B-0.38 C \\
& +4.89 A B-7.09 \times 10^{-3} A C+0.04 B C \\
& -2.43 \times 10^{-3} A^{2}+1.20 B^{2}+6.87 \times 10^{-3} C^{2}
\end{aligned}
$$

The results of ANOVA and fitness of the quadratic model as well as the effect of individual terms and their interaction on the chosen responses are presented in Table 3 .

The Fisher $F$-test $\left(F_{\text {model }}=35.05\right)$ with a very low probability value $\left[\left(P_{\text {model }}>F\right)<0.0001\right]$ shows a very high significance of the regression model at $95 \%$ confidence level.

The " $P$-value" less than 0.05 indicated that the particular model term is statistically significant. In Table $\mathbf{3}$ all the three model terms studied i.e. temperature $(A)$, glycerol to oil mass ratio $(B)$ and reaction time $(C)$ were found to have significant influence on the efficiency of glycerolysis. The interaction between temperature and time and quadratic terms $A^{2}$ and $C^{2}$ were also found to be significant. The relatively low value of the coefficient of variation $(C V=1.09 \%)$ indicates a good precision and reliability of the experiments carried out. The lack of fit test with $P$-value of 0.0623 , was not significant $(P$-value $>0.05$ is not significant) demonstrating that the model satisfactorily fitted the experimental data. Insignificant lack of fit is good, since a significant lack of fit indicates that there might be contribution in the regressor-response relationship that is not accounted for by the model [17]. The value of the determination coefficient $R^{2}=0.9693$ means only $3.075 \%$ of the total variations are not explained by the model. The value of the adjusted determination coefficient (Adj. $R^{2}=0.9416$ ) is also very high which supports the model [18].

3.1.1. Effects of Parameters on Glycerolysis Efficiency Figure 2(a) shows the response of the interactive factors 
Table 2. Experimental design and their corresponding results.

\begin{tabular}{|c|c|c|c|c|c|c|}
\hline \multirow{2}{*}{ Run } & \multirow{2}{*}{ Point type } & \multicolumn{3}{|c|}{ Level of variables (Actual) } & \multirow[t]{2}{*}{ Efficiency $(\%)$} & \multirow[t]{2}{*}{ Final FFA $(\%)$} \\
\hline & & Temperature, $A(\mathrm{wt} \%)$ & Glycerol to oil mass ratio, $B(\mathrm{~g} / \mathrm{g})$ & Time, $C(\min )$ & & \\
\hline 1 & Centre & 60 & 1.50 & 60 & 91.700 & 0.408 \\
\hline 2 & Centre & 60 & 1.50 & 60 & 91.809 & 0.403 \\
\hline 3 & Centre & 60 & 1.50 & 60 & 91.700 & 0.408 \\
\hline 4 & Centre & 60 & 1.50 & 60 & 90.203 & 0.482 \\
\hline 5 & Centre & 60 & 1.50 & 60 & 91.620 & 0.412 \\
\hline 6 & Centre & 60 & 1.50 & 60 & 91.565 & 0.415 \\
\hline 7 & Axial & 60 & 2.34 & 60 & 97.280 & 0.134 \\
\hline 8 & Axial & 60 & 0.66 & 60 & 87.573 & 0.611 \\
\hline 9 & Axial & 90 & 1.50 & 60 & 93.682 & 0.311 \\
\hline 10 & Axial & 60 & 1.50 & 35 & 94.660 & 0.263 \\
\hline 11 & Axial & 30 & 1.50 & 60 & 85.020 & 0.737 \\
\hline 12 & Axial & 60 & 1.50 & 85 & 97.236 & 0.136 \\
\hline 13 & Fact & 78 & 1.00 & 45 & 91.422 & 0.422 \\
\hline 14 & Fact & 78 & 2.00 & 45 & 97.880 & 0.104 \\
\hline 15 & Fact & 78 & 2.00 & 75 & 98.282 & 0.085 \\
\hline 16 & Fact & 42 & 2.00 & 45 & 91.220 & 0.432 \\
\hline 17 & Fact & 42 & 1.00 & 75 & 90.226 & 0.481 \\
\hline 18 & Fact & 42 & 1.00 & 45 & 83.394 & 0.817 \\
\hline 19 & Fact & 78 & 1.00 & 75 & 89.045 & 0.539 \\
\hline 20 & Fact & 42 & 2.00 & 75 & 97.744 & 0.111 \\
\hline
\end{tabular}

of temperature and mass ratio after 60 minutes of reaction. The three dimension response surface plots indicate that glycerolysis efficiency increases directly and proportionally to both reaction temperature and glycerol to oil mass ratio after 60 minutes of reaction time.

In Figure 2(b), the efficiency of glycerolysis increases with time at low reaction temperature; this means operating at low temperature, say room temperature, $30^{\circ} \mathrm{C}$ $34^{\circ} \mathrm{C}$ would require longer time to achieve high efficiency. At high reaction temperature, high glycerolysis efficiency can be obtained within short reaction time. This is due to the fact that, any temperature increase for the reaction will increase mass transfer in the phase containing triglycerides to the glycerin phase and increases solubility of both phases [10]. At any given glycerol to oil mass ratio, glycerolysis efficiency follows a curvilinear relationship with reaction time at when the reaction temperature is fixed at $60^{\circ} \mathrm{C}$, this means high glycerolysis efficiency can be attained by operating at the maximum glycerol to oil mass ratio and reaction time at $2.34 \mathrm{~g} / \mathrm{g}$ and 85 minutes respectively as in Figure 2(c).

\subsubsection{Optimization and Model Validation for Jatropha Oil Glycerolysis Efficiency}

The process optimization was done using the numerical features of the Design-Expert ${ }^{\circledR}$ 7. The parameters involved in optimization were set within the range between low and high while the glycerolysis efficiency was set at maximum value. The software predicted the following optimum conditions, namely, temperature of $65^{\circ} \mathrm{C}$, glycerol to oil mass ratio of $2.24 \mathrm{~g} / \mathrm{g}$ and reaction time of 73 min giving a glycerolysis efficiency of $99.72 \%$. The optimum conditions were tried experimentally and gave an average glycerolysis efficiency of $98.67 \%$ (corresponding to $0.0654 \%$ of FFA) which is $1.05 \%$ less than the predicted value of $99.72 \%$.

Several authors have worked on the glycerolysis as a pre-treatment of high free fatty acid with acidic catalysts as summaries in Table 4. However, they all used temperature above $120^{\circ} \mathrm{C}$ and more than 120 minutes of reaction time. The application of base catalyst which is said to be more effective has made it possible to run the 
Table 3. Analysis of variance (ANOVA) for model regression.

\begin{tabular}{|c|c|c|c|c|c|}
\hline Sources of variations & Sum of squares & Degrees of freedom & Mean square & $F$-value & $P$-value $\operatorname{Prob}>F$ \\
\hline Model & 320.53 & 9 & 35.61 & 35.05 & $<0.0001$ \\
\hline A-Temperature & 59.95 & 1 & 59.95 & 59.01 & $<0.0001$ \\
\hline$B$-Mass Ratio (g/g) & 164.27 & 1 & 164.27 & 161.68 & $<0.0001$ \\
\hline$C$-Time (min) & 18.08 & 1 & 18.08 & 17.79 & 0.0018 \\
\hline$A B$ & 0.015 & 1 & 0.015 & 0.015 & 0.9042 \\
\hline$A C$ & 29.38 & 1 & 29.38 & 28.92 & 0.0003 \\
\hline$B C$ & 0.76 & 1 & 0.76 & 0.75 & 0.4063 \\
\hline$A^{2}$ & 8.93 & 1 & 8.93 & 8.79 & 0.0142 \\
\hline$B^{2}$ & 1.30 & 1 & 1.30 & 1.28 & 0.2848 \\
\hline$C^{2}$ & 34.40 & 1 & 34.40 & 33.86 & 0.0002 \\
\hline Residual & 10.16 & 10 & 1.02 & & \\
\hline Lack of Fit & 8.31 & 5 & 1.66 & 4.5 & 0.0623 \\
\hline Pure Error & 1.85 & 5 & 0.37 & & \\
\hline Cor Total & 330.69 & 19 & & & \\
\hline Std. dev. & 1.01 & & $R$-Squared & 0.9693 & \\
\hline Mean & 92.16 & & Adjusted $R^{2}$ & 0.9416 & \\
\hline Coefficient of Variation $(\mathrm{CV})$ & 1.09 & & Predicted $R^{2}$ & 0.7954 & \\
\hline PRESS & 67.67 & & Adequate Precision & 20.122 & \\
\hline
\end{tabular}

Table 4. The effect of chemical re-esterification on the final amount of FFA.

\begin{tabular}{cccccccc}
\hline Type of oil & Time $(\mathrm{h})$ & Temperature $\left({ }^{\circ} \mathrm{C}\right)$ & Type of Catalyst & Excess Glycerol (\%) & Initial FFA (\%) & Final FFA (\%) & Sources \\
\hline Rice Bran oil & 6 & 200 & P-toluene sulphonic acid & 50 & 15.3 & 1.6 & {$[20]$} \\
Rice Bran oil & 6 & 200 & P-toluene sulphonic acid & 50 & 20.5 & 3.1 & 3.0 \\
Rice Bran oil & 4 & 200 & $\mathrm{SnCl}_{2}$ & 70 & 24.3 & {$[21]$} \\
Rubber seed oil & 6 & 200 & $\mathrm{SnCl}_{2}$ & 4.3 & 37.69 & 1.5 & {$[22]$} \\
Waste cooking oil & 4 & 200 & $\mathrm{SO}_{4}^{2-} / \mathrm{ZrO}_{2}-\mathrm{Al}_{2} \mathrm{O}_{3}$ & 70 & 44.42 & 0.71 & {$[23]$} \\
\hline
\end{tabular}

glycerolysis at low temperature in this study [19].

\subsection{Transesterification}

The transesterification process gives a conversion of $97.873 \%$, following the alkali-catalyzed transesterification using the pre-treated jatropha oil with $0.0654 \%$ of FFA. The fuel properties of biodiesel tested are summarized in Table 5. It can be seen that jatropha biodiesel fuel properties are within the limits prescribed in the American and European standards for biodiesel i.e. ASTM D6751 and EN 14214 standards respectively.

\section{Conclusion}

The study revealed that the chemical re-esterification (glycerolysis) can be used as a pre-treatment method for high FFA feedstock for biodiesel production. The high FFA (4.54\%) level of crude jatropha oil could be reduced to 0.0654 with 73 minutes, glycerol to oil mass ratio of $2.24 \mathrm{~g} / \mathrm{g}$ at $65^{\circ} \mathrm{C}$ as optimum conditions for glycerolysis. The glycerolysis has shown a potential to reduce the FFA to less than $3 \%$ which is required for alkali-catalyzed transesterification. Alkali-catalyzed transesterification of the pre-treated oil produced biodiesel with fuel properties 
Table 5. Fuel properties of jatropha biodiesel.

\begin{tabular}{|c|c|c|c|c|}
\hline \multirow{2}{*}{ Property } & \multirow{2}{*}{ Unit } & \multirow{2}{*}{ Jatropha biodiesel } & \multicolumn{2}{|c|}{ Biodiesel standards } \\
\hline & & & ASTM D6751 & EN 14214 \\
\hline Viscosity at $40^{\circ} \mathrm{C}$ & $\mathrm{mm}^{2} / \mathrm{s}$ & 4.0 & $1.9-6.0$ & $3.5-5.0$ \\
\hline Acid value & $\mathrm{mg} \mathrm{KOH} / \mathrm{g}$ & 0.074 & $<0.8$ & $<0.5$ \\
\hline Gross Calorific value & $\mathrm{MJ} / \mathrm{kg}$ & 39.870 & Not specified & Not specified \\
\hline Iodine Value & $\mathrm{g} \mathrm{I}_{2} / 100 \mathrm{~g}$ & 105.9 & Not specified & $<120$ \\
\hline FAME content & $\%$ & 97.873 & Not specified & $>96.5$ \\
\hline Density at $15^{\circ} \mathrm{C}$ & $\mathrm{kg} / \mathrm{m}^{3}$ & 0.8703 & Not specified & $0.860-0.900$ \\
\hline Oxidation stability, at $110^{\circ} \mathrm{C}$ & $\mathrm{h}$ & 8.24 & Not specified & $>6$ \\
\hline
\end{tabular}

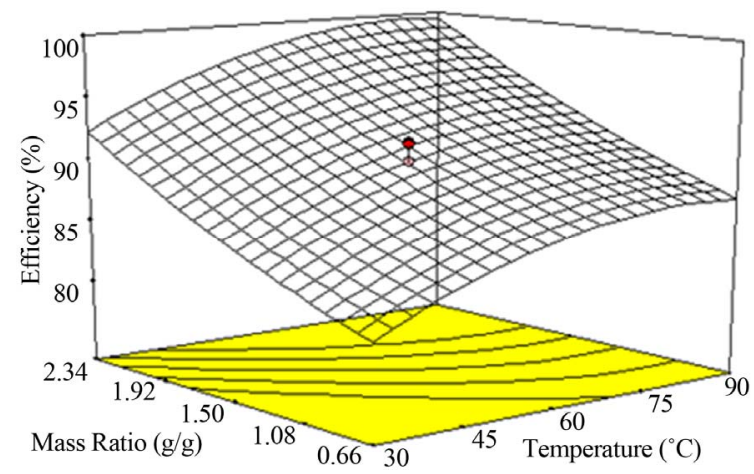

(a)

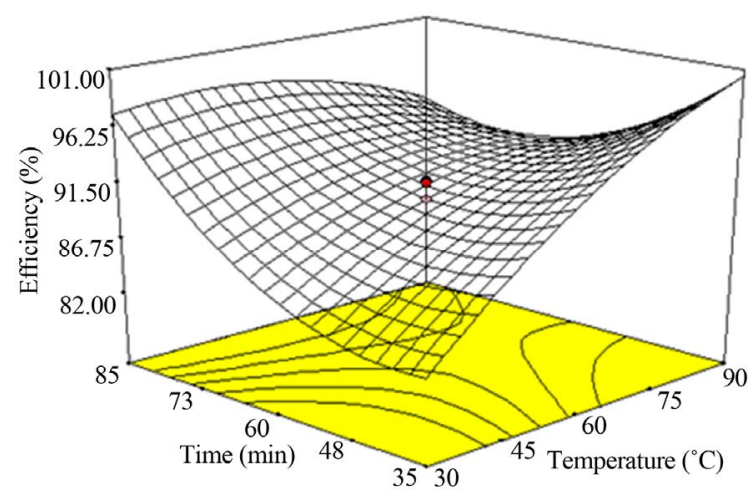

(b)

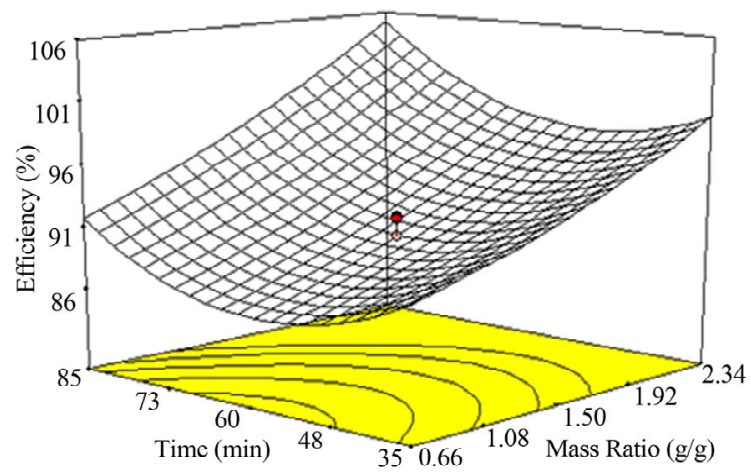

(c)

Figure 2. Effect of reaction temperature, time and glycerol to oil mass ratio on jatropha oil glycerolysis efficiency. that satisfy both the ASTM D6751 and EN 14214 standards for biodiesel. Glycerolysis can utilize the glycerol from the transesterification process and thus lower the cost of biodiesel production.

\section{Acknowledgements}

The authors wish to acknowledge the Universiti Sains Malaysia for laboratory work and ESEPRIT project at University of Dar es Salaam under for financial support

\section{REFERENCES}

[1] A. B. Chhetri, M. S. Tango, S. M. Budge, K. C. Watts, and M. R. Islam, "Non-Edible Plant Oils as New Sources for Biodiesel Production," International Journal of $\mathrm{Mo}$ lecular Sciences, Vol. 9, No. 2, 2008, pp. 169-180. http://dx.doi.org/10.3390/ijms9020169

[2] T. Krawczyk, "Biodiesel-Alternative Fuel Makes Inroads but Hurdles Remain," Inform, Vol. 7, 1996, pp. 801-815.

[3] Z. Helwani, M. R. Othman, N. Aziz, W. J. N. Fernando, and J. Kim, "Technologies for Production of Biodiesel Focusing on Green Catalytic Techniques: A Review," Fuel Processing Technology, Vol. 90, No. 12, 2009, pp. 1502-1514.

[4] D. Bacovsky, W. Körbitz, M. Mittelbach and M. Wörgetter, "Biodiesel Production: Technologies and European Providers," Report T39-B6, 2007.

[5] Y. Zhang, M. A. Dube, D. D. McLean and M. Kates, "Biodiesel Production from Waste Cooking Oil: 1. Process Design and Technological Assessment," Bioresource Technology, Vol. 89, No. 1, 2003, pp. 1-16. http://dx.doi.org/10.1016/S0960-8524(03)00040-3

[6] M. A. Hanna and F. Ma, "Biodiesel Production: A Review," Bioresource Technology, Vol. 70, 1999, pp. 1-15.

[7] G. Knothe, J. Van Gerpen and J. Krahl, "Basics of the Transesterification Reaction," In: The Biodiesel Handbook, AOCS Press, Champaign, 2005, pp. 26-41.

[8] M. Dorado, E. Ballesteros, J. De Almeida, C. Schellert, H. Löhrlein and R. Krause, "An Alkali-Catalyzed Transesterification Process for High Free Fatty Acid Waste Oils," Transactions of the ASAE, Vol. 45, 2002, pp. 525-529. 
[9] A. J. C. Anderson, "Refining of Oils and Fats for Edible Purposes," 2nd Edition, Pergamon Press, London, 1962, pp. 92-103.

[10] P. Felizardo, J. Machado, D. Vergueiro, M. J. N. Correia, J. P. Gomes and J. M. Bordado, "Study on the Glycerolysis Reaction of High Free Fatty Acid Oils for Use as Biodiesel Feedstock," Fuel Processing Technology, Vol. 92, No. 6, 2011, pp. 1225-1229. http://dx.doi.org/10.1016/j.fuproc.2011.01.020

[11] N. O. V. Sonntag, "Glycerolysis of Fats and Methyl Esters-Status, Review and Critique," Journal of the American Oil Chemists' Society, Vol. 59, 1982, pp. 795-802.

[12] H. Noureddini, D. Harkey and M. Gutsman, "A Continuous Process for the Glycerolysis of Soybean Oil," Journal of the American Oil Chemists' Society, Vol. 81, 2004, pp. 203-207.

[13] A. Khuri and J. A. Comell, "Response Surfaces Design and Analysis," Marcel Dekker, New York, 1987.

[14] R. H. Myers and D. C. Montgomery, "Response Surface Methodology Process and Product Optimization Using Designed Experiments," Wiley, New York, 2002.

[15] ASTM, "Petroleum Products, Lubricants and Fossil Fuels," In: Annual Book of ASTM Standards, American Society for Testing and Materials, 2004.

[16] DIN EN14214, "Automotive Fuels-Fatty Acid Methyl Esters (FAME) for Diesel Engines, Requirements and Test Methods," European Standards, 2003.

[17] M. Zabeti, W. M. A. W. Daud and M. K. Aroua, "Optimization of the Activity of $\mathrm{CaO} / \mathrm{Al}_{2} \mathrm{O}_{3}$ Catalyst for Biodiesel Production Using Response Surface Methodology," Applied Catalysis A: General, Vol. 366, No. 1,
2009, pp. 154-159.

http://dx.doi.org/10.1016/j.apcata.2009.06.047

[18] M. Saqib, M. W. Mumtaz, A. Mahmood and M. I. Abdullah, "Optimized Biodiesel Production and Environmental Assessment of Produced Biodiesel," Biotechnology and Bioprocess Engineering, Vol. 17, No. 3, 2012, pp. 617 623. http://dx.doi.org/10.1007/s12257-011-0569-6

[19] A. C. Kumoro, "Experimental and Modeling Studies of the Reaction Kinetics of Alkaline-Catalyzed Used Frying Oil Glycerolysis Using Isopropyl Alcohol as a Reaction Solvent," Research Journal of Applied Sciences, Engineering and Technology, Vol. 4, 2012, pp. 869-876.

[20] A. C. Bhattacharyya and D. K. Bhattacharyya, "Deacidification of High FFA Rice Bran Oil by Reesterification and Alkali Neutralization," Journal of the American Oil Chemists' Society, Vol. 64, 1987, pp. 128-131.

[21] S. Singh and R. P. Singh, "Deacidification of High Free fatty Acid-Containing Rice Bran Oil by Non-Conventional Reesterification Process," Journal of Oleo Science, Vol. 58, No. 2, 2009, pp. 53-56.

[22] R. O. Ebewele, A. F. Iyayi and F. K. Hymore, "Deacidification of High Acidic Rubber Seed Oil by Reesterification with Glycerol," International Journal of the Physical Sciences, Vol. 5, 2010, pp. 841-846.

[23] Y. Wang, S. Ma, L. Wang, S. Tang, W. W. Riley and M. J. Reaney, "Solid Superacid Catalyzed Glycerol Esterification of Free Fatty Acids in Waste Cooking Oil for Biodiesel Production," European Journal of Lipid Science and Technology, Vol. 114, 2012, pp. 315-324. http://dx.doi.org/10.1002/ejlt.201100111 